\title{
Зарубежные программы умной реиндустриализации: варианты для России
}

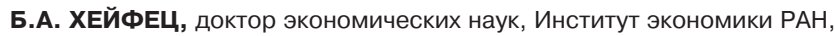
Финансовый университет при Правительстве РФ.

E-mail: bah412@rambler.ru

В.Ю. ЧЕРНОВА, кандидат экономических наук, Российский университет дружбы народов, Москва. E-mail: veronika_urievna@mail.ru

Аннотация. В статье рассматривается опыт зарубежных стран - Франции и Германии, Китая, Индии - в реализации структурной и технологической модернизации экономики с помощью новых инструментов стратегического управления. Несмотря на имеющиеся различия, у всех стран на первое место выходят приоритеты ускоренного внедрения технологий четвертой промышленной революции, нацеленность на осуществление принципиальных структурных сдвигов и ориентация на достижение конкретных результатов в среднесрочной перспективе. Показано, что, несмотря на неоднозначность достигнутых результатов, ни одна из стран не отказалась от принятых программ и продолжает их совершенствование с целью более адекватной реакции на технологический прогресс, связанный с четвертой промышленной революцией. Задачи, поставленные в зарубежных программах умной реиндустриализации, очень актуальны и для российской экономики и заслуживают внимательного изучения и адаптации к нашим реалиям. Отмечено, что существенными недостатками нацпроектов являются отсутствие системы мониторинга и контроля за выполнением поставленных целей и чрезмерно растянутые сроки на «раскачку»; отсутствие проработанной долгосрочной стратегии социально-экономического развития, а также проработанных планов в ряде ключевых областей, определяющих цифровое будущее страны. Делается вывод о необходимости внедрения инструментов стратегического планирования в национальные проекты для целенаправленного преобразования структуры российской экономики и ее экспорта.

Ключевые слова: умная реиндустриализация; стратегии реиндустриализации; индустрия 4.0; структурная и технологическая модернизация; структурная политика; «Сделано в России 2030»

\section{Программы умной реиндустриализации}

Глобальный финансово-экономический кризис 2008-2009 гг. показал острую необходимость ускорения структурной и технологической модернизации на основе новых технологий, вызвавших 
четвертую промышленную революцию ${ }^{1}$ [Шваб, 2016]. Эти технологии качественно изменят сферу материального производства и всю жизнь общества, приведут к серьезным сдвигам в системе международного разделения труда.

Например, в авиастроении создание платформы быстрого моделирования может сократить время проектирования и проектную доработку на 20\%. Интернет вещей позволяет в реальном времени передавать и обрабатывать данные о качественных характеристиках оборудования, производственных процессов, а порой - даже организовать их дистанционную наладку, что приводит к минимизации дефектов, производственных отходов и времени простоев. Современные роботы справляются с опасными работами и минимизируют риски аварий, трехмерная печать способна создавать сложные, многокомпонентные детали и конечный товар, а новые компьютерные приложения оптимизируют кооперационные и сбытовые цепочки ${ }^{2}$.

Все это оказывает серьезное влияние на экономические процессы. Так, внедрение аддитивных технологий (прежде всего, связанных с 3D-принтерами) позволяет локализовать разнообразные производства в странах с небольшими рынками сбыта, где традиционные технологии были бы неэффективны. Фактически они укорачивают глобальные производственные цепочки и, соответственно, объемы трансграничной торговли. Согласно прогнозу банка ING, бум 3D-печати будет способствовать увеличению местного производства промышленных товаров, что к 2040 г. может понизить обороты глобальной торговли на $40 \%{ }^{3}$.

Для того чтобы эффективнее ответить на новые вызовы технологического прогресса во многих странах мира (не только

\footnotetext{
${ }^{1}$ Четвертая промышленная революция - собирательный термин, характеризующий весь комплекс нынешних и будущих преобразований, вызванных внедрением как новых, но уже известных технологий (искусственный интеллект, 3D-печать, робототехника, виртуальная и дополненная реальность, нейро- и биотехнологии, передовые материалы и др.), так и технологий, неизвестных в настоящее время.

${ }^{2}$ McKinsey (2017). Making it in America: Revitalizing US manufacturing. [Эл. pecypc]. URL: https://www.mckinsey.com/ /media/McKinsey/Featured\%20Insights/Americas/ Making\%20it\%20in\%20America\%20Revitalizing\%20US\%20manufacturing/Making-it-inAmerica-Revitalizing-US-manufacturing-Full-report.ashx (дата обращения: 20.09.2018).

${ }^{3}$ Wass S. (2017). 3D printing could wipe out $40 \%$ of world trade by 2040.3 October. [Эл. pecypc]. URL: https://www.gtreview.com/.../global/3d-printing-could-wipe-out-40-of=worldtrade-by-2040/ (дата обращения: 10.09.2018).
} 
развитых ${ }^{4}$, но и с переходной экономикой5), были разработаны стратегические программы создания предпосылок для таких преобразований.

Хотя многие программы затрагивают всю экономику, у них есть свои приоритеты, которые, несмотря на все различия, на первое место ставят задачи ускоренного внедрения технологий четвертой промышленной революции. В этом смысле их можно назвать инструментом проведения селективной структурной политики.

Основная часть структурных и технологических преобразований, предусматриваемых этими программами, касается промышленности и связанных с ней секторов услуг, которые будет создавать предпосылки для аналогичных сдвигов в других секторах экономики. Поэтому с полным основанием их можно назвать и программами реиндустриализации, а, учитывая их селективный и инновационный характер - программами умной реиндустриализациии.

Показательно, что в опубликованном в январе 2018 г. докладе экспертов ВЭФ «Готовность к производству будущего» страны, принявшие эти программы, опережают Россию (таблица). Индекс готовности к производству будущего показывает способность страны извлекать выгоду из будущих производственных возможностей, смягчать риски и проблемы, гибко реагируя на неизвестные будущие шоки и состоит из двух интегральных индикаторов: 1) структура производства, характеризующего текущий базовый уровень производства и 2) драйверы производства, характеризующего ключевые факторы, которые позволят преобразовать производственную систему страны и извлечь выгоду от внедрения технологий четвертой промышленной революции ${ }^{6}$.

\footnotetext{
${ }^{4}$ Программы Nouvelle France Industrielle во Франции, Industrie 4.0 в Германии, “igh Value Manufacturing Catapult в Великобритании, Industrial Value Chain Initiative в Японии, Fabbrica del Futuro в Италии, Smart Factory”в Нидерландах, Industria Conectada 4.0 в Испании, Prumysl 4.0. в Чехии.

${ }^{5}$ Программы Manufacturing Innovation 3.0 в Республике Корея, Made in China 2025 в Китае, Make in India в Индии, Smart Nation Programme в Сингапуре, National Industry 4.0 Policy в Малайзии, Национальная технологическая инициатива в Казахстане.

${ }^{6}$ Более подробно см. WEF (2018). The Readiness for the Future of Production. WEF. Report 2018. Insight Report. [Эл. pecypc]. URL: http://www3.weforum.org/docs/FOP Readiness_Report_2018.pdf (дата обращения: 07.09.2018).
} 
Место России и ряда зарубежных стран по ключевым критериям готовности к производству будущего

\begin{tabular}{|c|c|c|c|c|c|c|}
\hline Показатель & Россия & Китай & Индия & $\begin{array}{l}\text { Республика } \\
\text { Корея }\end{array}$ & Франция & Германия \\
\hline \multicolumn{7}{|c|}{ Структура производства (текущий базовый уровень производства) } \\
\hline Общая оценка & 35 & 5 & 30 & 2 & 18 & 3 \\
\hline $\begin{array}{l}\text { Сложность струк- } \\
\text { туры производства }\end{array}$ & 44 & 27 & 48 & 4 & 15 & 2 \\
\hline Масштаб & 25 & 1 & 9 & 2 & 28 & 12 \\
\hline \multicolumn{7}{|c|}{$\begin{array}{c}\text { Драйверы производства (ключевые факторы, которые позволят преобразовать производст- } \\
\text { венную систему страны и извлечь выгоду от внедрения технологий четвертой промышленной } \\
\text { революции) } \\
\end{array}$} \\
\hline Общая оценка & 43 & 25 & 44 & 21 & 10 & 6 \\
\hline $\begin{array}{l}\text { Технологии и ин- } \\
\text { новации }\end{array}$ & 39 & 25 & 34 & 17 & 14 & 8 \\
\hline $\begin{array}{l}\text { Человеческий ка- } \\
\text { питал }\end{array}$ & 25 & 40 & 63 & 30 & 23 & 7 \\
\hline $\begin{array}{l}\text { Глобальная торгов- } \\
\text { ля и инвестиции }\end{array}$ & 49 & 9 & 55 & 17 & 14 & 8 \\
\hline Институты & 87 & 61 & 54 & 25 & 21 & 14 \\
\hline $\begin{array}{l}\text { Стабильные pe- } \\
\text { сурсы }\end{array}$ & 35 & 66 & 96 & 46 & 10 & 13 \\
\hline Общий спрос & 20 & 2 & 5 & 13 & 10 & 4 \\
\hline
\end{tabular}

Источник: WEF, $2018^{7}$.

Все это говорит о том, что задачи, поставленные в зарубежных программах умной реиндустриализации, актуальны и для российской экономики. Рассмотрим некоторые из них.

\section{Индустрия 4,0 в Германии}

Тенденции перехода к умной реиндустриализации Германии стали заметны после мирового финансового кризиса 2008-2009 гг. Одним из преимуществ экономики Германии всегда являлся высокий удельный вес промышленности в ВВП по сравнению с другими развитыми странами, где основную роль играет сфера услуг.

Ведущее положение страны в мировой экономике обеспечивают ее традиционные отрасли - машино- и автомобилестроение, химическая и фармацевтическая промышленность, отрасли транспортно-логистического комплекса и связанные с ними

${ }^{7}$ WEF (2018). The Readiness for the Future of Production. WEF. Report. Insight Report. [Эл. ресурс]. URL: http://www3.weforum.org/docs/FOP_Readiness_Report_2018.pdf (дата обращения: 07.09.2018). 
секторы, выпускающие специализированное оборудование и комплексные автоматизированные системы. Продукцию Германии отличают высокое качество, инновационность и высокая производительность, что является результатом обширных инвестиций в образование и исследования и разработки $(R \& D)$.

Поскольку промышленное производство сохраняет свою ключевую роль в экономике и занятости Германии, страна не может оставаться удовлетворенной имеющимися достижениями. Возрастающая глобальная конкуренция, инвестиции в новые технологии и разработки, которые активно осуществляют другие страны, сказываются на ее конкурентоспособности.

Впервые идея Industrie 4.0 и ее главного элемента «умных предприятий» была представлена на Ганноверской ярмарке 2011 г. немецкими учеными и политиками Х. Кагерманом, В.-Д. Лукасом и В. Вальстером [Белов, 2016]. В 2012 г. правительство ФРГ в рамках «Стратегии в области высоких технологий 2020» приняло инновационную программу Industrie $4.0^{8}$, концепция которой зарождалась как инициатива в рамках «Плана действий по осуществлению государственной стратегии высокотехнологичного развития до 2020 г.», нацеленной на ускорение темпов производства.

В отличие от других стран, которые в разной степени приступили к разработке и реализации программ четвертой промышленной революции и ставят перед собой задачу модернизации или индустриализации промышленности, Германию в первую очередь заботит сохранение ее лидирующих позиций в промышленном секторе мировой экономики. Этому призваны содействовать дальнейшее стимулирование инноваций в промышленность и развитие Industrie $4.0^{9}$.

В качестве мер стимулирования инноваций названы:

- создание высокоэффективной системы акторов, включающей государственные и частные компании, отраслевые ассоциации, финансовые институты, учебные заведения, глобальные трейдеры и организации потребителей;

\footnotetext{
${ }^{8}$ Ideas. Innovation. Prosperity. High-Tech Strategy 2020 for Germany. [Эл. pecypc]. URL: file://Users/z/Downloads/hts_2020_en.pdf (дата обращения: 13.10.2018).

${ }^{9}$ BMWI (2018). Annual Economic Report 2018. A strengthened economy ready to embrace the future. [Эл. pecypc]. URL: https://www.bmwi.de/Redaktion/EN/Publikationen/ jahreswirtschaftsbericht-2018.pdf?_blob=publicationFile\&v=2 (дата обращения: 05.10.2018).
} 
- увеличение доли высококвалифицированной рабочей силы.

Кроме этого, программой Industrie 4.0 предусмотрены налоговые и амортизационные льготы для стимулирования инвестиций, а также меры содействия продвижению на мировой рынок бренда Industrie 4.0. Для стимулирования развития ключевых секторов, в частности микроэлектроники, в Германии используется государственное субсидирование, на которое с 2017 г. по 2019 г. выделена общая сумма в 1 млрд евро ${ }^{10}$.

Для повышения привлекательности Германии как места размещения новых производств и возвращения из-за рубежа ранее выведенных туда предприятий, делается акцент на развитии современных технологий: встроенные системы, умные заводы, облачные вычисления, IT-безопасность. Благодаря использованию этих технологий дополнительная совокупная добавленная стоимость, производимая Германией, составит 425 млрд евро. Прогнозы предполагают увеличение производительности до $30 \%$, годовой прирост эффективности - на $3,3 \%$ и снижение затрат - на 2,6\% в год. Секторами, которые получат наибольшую выгоду в следующие пять лет, являются автомобильная промышленность с увеличением выручки на 52,5 млрд евро (13,6\%), машиностроение (32 млрд евро или 13,2\%), обрабатывающая (30 млрд евро или 8,1\%), электронная промышленность $(23,5$ млрд евро или 13\%) и ИКТ (15 млрд евро или $13,4 \%)^{11}$.

К числу потенциальных эффектов от реализации стратегии Industrie 4.0 относятся также:

- рост конкурентоспособности германской экономики и ее отдельных секторов (за счет повышения эффективности и скорости производственных процессов и роста качества продукции);

- изменение места немецких предприятий и секторов промышленности в глобальных цепочках добавленной стоимости и повышение эффективности глобальных цепочек;

${ }^{10}$ BMWI (2019). A Digital Strategy 2025. [Эл. pecypc]. URL: https://www.de.digital/ DIGITAL/Redaktion/EN/Publikation/digital-strategy-2025.pdf?_blob=publicationFile\&v=9 (дата обращения: 17.05.2019).

${ }^{11}$ BMWI (2019). A Digital Strategy 2025. [Эл. pecypc]. URL: https://www.de.digital/ DIGITAL/Redaktion/EN/Publikation/digital-strategy-2025.pdf?_blob=publicationFile \&v=9 (дата обращения: 17.05.2019). 
- развитие новых продуктов и бизнес-процессов с использованием интернет-технологий, придающих импульс экономическому росту ${ }^{12}$.

В рамках стратегии предусмотрен комплекс мероприятий в области подготовки кадров, включая рост числа центров подготовки и научно-исследовательских центров, а также разработку новых учебных курсов ${ }^{13}$. Региональные центры передового опыта «Mittelstand 4.0», финансируемые Федеральным министерством экономики и энергетики, и Центр передового опыта по «цифровизации умелых ремесел» оказывают содействие малому и среднему бизнесу (информационно-консультационную поддержка, обучение, возможность для тестирования приложений Industrie 4.0). Кроме того, демонстрационные и обучающие фабрики помогают компаниям апробировать их технологии, продукты или интерфейсы. В специализированных центрах германских университетов и НИИ имеется ряд испытательных стендов, где сложные производственные и логистические системы оцениваются, тестируются и совершенствуются в реальных условиях ${ }^{14}$.

Параллельно в стране разрабатываются механизмы управления цифровыми преобразованиями, внедряются новые правила, регулирующие цифровую экономику, экономику совместного использования и цифровые платформы. Федеральное министерство экономики и энергетики инициировало процесс широкого обсуждения так называемой «Белой книги по цифровым платформам», в которой излагаются предложения по политике цифрового регулирования. К числу ключевых аспектов последнего относятся обеспечение инклюзивного роста экономики, защита личных прав граждан и суверенитет данных ${ }^{15}$.

\footnotetext{
${ }^{12}$ GTAI (2018). Industrie 4.0 - Germany market report and outlook. [Эл. pecypc]. URL: https://www.gtai.de/GTAI/Content/EN/Invest/_SharedDocs/Downloads/GTAI/Industryoverviews/industrie 4.0-germany-market-outlook-progress-report-en.pdf?v=12 (дата обращения: 03.10.2018).

${ }^{13}$ EC (2017). Germany: Industrie 4.0 January 2017. [Эл. pecypc]. URL: https://ec.europa. eu/growth/tools-databases/dem/monitor/sites/default/files/DTM_Industrie\%204.0.pdf (дата обращения: 17.10.2018).

${ }^{14}$ BMWI (2019). Industrie 4.0. [Эл. pecypc]. URL: https://www.bmwi.de/Redaktion/EN/ Dossier/industrie-40.html (дата обращения: 16.05.2019).

${ }^{15}$ BMWI (2019). Taking control of the digital transformation. [Эл. pecypc]. URL: https://www.bmwi.de/Redaktion/EN/Dossier/digitisation.html (дата обращения: 16.05.2019).
} 
С июля 2017 г. в Германии создается «цифровое правительство», для чего выявляются и оцифровываются наиболее важные и часто используемые административные услуги.

Несмотря на определенные успехи в цифровизации экономики Германии (цифровизированы $28 \%$ коммерческих предприятий, $39 \%$ используют «большие данные») и значительные инвестиции частного сектора (4,6 млрд евро в 2017 г. $)^{16}$, только шесть из десяти компаний в Германии готовы к цифровым трасформациям Industry $4.0^{17}$. Более поздние исследования показали, что эффект от внедрения цифровых технологий в традиционных отраслях экономики отмечен только в 7-11\% компаний ${ }^{18}$

\section{Программа «Новая промышленная Франция»}

Позиции Франции в мировом производственном секторе в течение последних десятилетий заметно пошатнулись вследствие распространения глобальных цепочек создания стоимости, особенно из-за снижения конкурентоспособности страны по сравнению с другими крупными производственными площадками. В результате произведенная во Франции добавленная стоимость обрабатывающей промышленности в процентах от ВВП сократилась с $17,7 \%$ в 1990 г. до $11,3 \%$ в 2016 г. ${ }^{19}$

В целях оживления и развития производственного сектора правительство Франции в 2013 г. разработало стратегию Nouvelle France Industrielle («Новая промышленная Франция») - программу инновационно-технологической модернизации, охватывающую 34 сектора национальной промышленности. В 2015 г. стартовал второй этап программы под названием Industrie du Futur $(I d F)$ или «Индустрия будущего», фокусирующийся на девяти приоритетных направлениях: медицина будущего, экомобильность, новые ресурсы, устойчивое развитие городов, транспорт завтрашнего дня, экономика данных, интеллектуальные объекты, цифровое

\footnotetext{
${ }^{16}$ BMWI (2019). Taking control of the digital transformation. [Эл. pecypc]. URL: https:/www.bmwi.de/Redaktion/EN/Dossier/digitisation.html (дата обращения: 16.05.2019).

${ }^{17}$ McKinsey (2015). Industry 4.0: How to navigate digitisation of the manufacturing sector [Эл. pecypc]. URL: http://www.forschungsnetzwerk.at/downloadpub/mck_industry_40_report. pdf (дата обращения: 16.05.2019).

${ }^{18}$ McKinsey (2018). Unlocking success in digital transformations [Эл. pecypc]. URL: https:/www.mckinsey.com/business-functions/organization/our-insights/unlocking-successin-digital-transformations (дата обращения: 16.05.2019).

${ }^{19}$ The Future of Manufacturing - France. P. 11. [Эл. pecypc]. URL: https://gmisummit.com/ wp-content/uploads/2018/06/20180627_GMIS-France_vF.pdf (дата обращения: 06.10.2018).
} 
доверие и умное производство продуктов питания. В отличие от Nouvelle France Industrielle, основной целью которой была модернизация промышленности, стимулирование инноваций и технологических нововведений, в Industrie du Futur акцент сделан на цифровизации отраслей промышленности, цифровой трансформации методов производства и организационных структур.

Однако, как и предыдущая стратегия 2013 г., Industrie du Futur охватывает широкий круг вопросов по большому количеству отраслей и технологий в отсутствие конкретных планов по реализации и финансированию, необходимых для достижения поставленных целей ${ }^{20}$.

Бюджет Industrie du Futur превышает бюджеты большинства европейских стран на аналогичные программы оживления промышленности, благодаря инвестициям частного сектора, которые должны пятикратно превысить государственное финансирование (5 млрд евро $)^{21}$.

Конкретный план внедрения Idf носит название Usine $d u$ Futur или Factory of the Future («Предприятие будущего») и предполагает модернизацию всей французской промышленности на основе новейших цифровых технологий. В реализацию этой инициативы вовлечены значительные кадровые ресурсы: более 500 специально подготовленных экспертов призваны оказывать поддержку малым и средним предприятиям в области проектирования, послепродажного обслуживания, производства и логистики. В 2016 г. их услугами воспользовались 3,4 тыс. предприятий, в 2017 г. - 4 тыс.

Помимо бизнеса, участниками программы Industrie $d u$ Futur являются инженерные школы, научно-технические институты и Национальный совет по промышленности Франции. Поддержка проектам в промышленности осуществляется по семи направлениям деятельности: цифровые технологии, виртуализация и Интернет вещей, трудовые ресурсы в промышленности будущего, 3D-печать, мониторинг и контроль,

\footnotetext{
${ }^{20}$ The Future of Manufacturing - France. P. 11. [Эл. pecypc]. URL:

https:/gmisummit.com/wp-content/uploads/2018/06/20180627_GMIS-France_vF.pdf (дата обращения: 06.10.2018).

${ }^{21}$ New Industrial France (2016). Building France's industrial future. [Эл. pecypc]. URL: https://www.economie.gouv.fr/files/files/PDF/web-dp-indus-ang.pdf (дата обращения: 03.10. 2018).
} 
новые материалы и ресурсы, автоматизация и робототехника, энергоэффективность.

В качестве мер поддержки во Франции используются амортизационные льготы (половина всех мер в стоимостном выражении), сниженные налоговые ставки на энергию для центров обработки данных, льготы по налогу на прибыль от защищенных авторским правом инноваций, которые были разработаны во Франции ${ }^{22}$, снижение налога на инвестиции в робототехнику и цифровые преобразования (3D-принтер, программное обеспечение для управления производством, подключенные датчики и пр.) для малого и среднего бизнеса с января 2019 г. до конца 2020 г., ${ }^{23}$ что позволит МСП вычитать из своего налогооблагаемого дохода до $40 \%$ себестоимости нового производственного оборудования и составляет сокращение расходов на инвестиции до $11 \%$, по данным правительства ${ }^{24}$.

Для координации на национальном уровне инициатив и проектов, направленных на модернизацию промышленности, а также для помощи бизнесу в интеграции новых концепций, создан альянс Industrie du Futur, в который в настоящее время входят 35 активных членов: академические организации; организации, занимающиеся технологическими исследованиями; профессиональные союзы ${ }^{25}$ и организации корпоративных финансов (финансирования бизнеса). Внутри альянса действуют рабочие группы, в задачи которых входит, в том числе, развитие реальных партнерств (ассоциаций работодателей, торговых палат и пр.).

Сквозной характер инициативы «Индустрия будущего» подкрепляется определением ключевых технологий, развитие которых будет способствовать росту конкурентоспособности страны (это определяется путем анализа мировых рынков

\footnotetext{
${ }^{22}$ Industrie du futur: l'Etat donne un coup de pouce aux PME. [Эл. pecypc]. URL:

https://www.challenges.fr/entreprise/industrie-du-futur-1-etat-donne-un-coup-de-pouceaux-pme_614190 (дата обращения: 16.05.2019).

${ }^{23}$ Comment le gouvernement veut accélérer l'industrie du futur. [Эл. pecypc]. URL:

https://www.usinenouvelle.com/editorial/le-gouvernement-veut-accelerer-l-industrie-dufutur.N743709 (дата обращения: 16.05.2019).

${ }^{24}$ Industrie du futur: 1'Etat donne un coup de pouce aux PME. [Эл. pecypc]. URL:

https://www.challenges.fr/entreprise/industrie-du-futur-l-etat-donne-un-coup-de-pouceaux-pme_614190 (дата обращения: 16.05.2019).

${ }^{25}$ Профсоюзы или их группы, в соответствии с французским законодательством, представляют собой организации, основной целью которых является представление и защита коллективных интересов промышленных, цифровых или сервисных компаний
} 
и прогнозирования их развития на среднесрочную перспективу). Большая часть ключевых технологий связана со всеми девятью приоритетными направлениями развития. Их регулярно актуализируемый перечень сопровождается списком основных заинтересованных сторон по каждой технологии и региону (промышленных предприятий, научно-исследовательских и академических институтов, кластеров, технических промышленных центров, энергетических компаний и др.).

В число ключевых технологий до 2020 г. включены технологии в сфере наноэлектроники, робототехники, 3D-печати, облачных вычислений, сотовая и тканевая инженерия, технологии иммунной системы и медицины будущего; технологии в сфере производства и транспорта традиционных и возобновляемых источников энергии, а также в области экономии ресурсов (энергосбережение в строительстве, интеллектуальные сети и др. $)^{26}$.

Краеугольным камнем успеха Industrie du Futur считается подготовка будущих поколений к выполнению новых задач. Немало внимания уделяется формированию международных стратегических партнерств.

Среди ключевых задач на ближайшую перспективу идеологи Industrie du Futur видят преобразование в производственные возможности имеющегося потенциала передовых технологических компаний (во Франции существует немалое количество стартапов в области 3D-программирования, интернета вещей, многие из которых уже активно инвестируют в передовое производство).

Кроме того, стоит задача восстановления национальной промышленной базы, путем релокализации французских предприятий из-за рубежа при помощи внедрения технологий Industrie du Futur.

В то же время программа Industrie du Futur не свободна от недостатков. Так, повышенное внимание к разработке новых технологий (в 2015 г. около 64\% инвестиций направлялись в НИОКР, программное обеспечение и базы данных) и недостаточное - к производственному сектору (всего около 27\% инвестиций в машины и оборудование, тогда как в Германии

\footnotetext{
${ }^{26}$ Créative Industry (2016). [Эл. pecypc]. URL: http://proxy-pubminefi.diffusion.finances. gouv.fr/pub/document/18/20849.pdf (дата обращения: 25.09.2018).
} 
на обновление основных фондов направляется $45 \%$ инвестиций, в Италии $-67 \%$ ), привели к тому, что технологический парк во Франции в среднем на десять лет старше, чем в Германии ${ }^{27}$.

Вовлечение в инновационную активность главным образом микро-, малых и средних предприятий происходит на фоне отсутствия внимания к предприятиям промежуточного размера (более 250 работников), хотя именно они являются двигателями роста французской экономики, и из-за своего масштаба способны занять сколько-нибудь значимую рыночную нишу, в том числе на экспортных рынках. Кроме того, малые предприятия Франции (в отличие, например, от немецких собратьев) не могут участвовать в неценовой конкуренции. В то же время приоритетные инвестиции в НИОКР не могут обеспечить неценовой конкурентоспособности продукции, которая определяется не только его инновационным контентом, но и дизайном, надежностью и репутацией производителей, качеством послепродажного обслуживания и др.

Однако, несмотря на существенные инвестиции, предоставленные кредиты (более 800 компаниям) и достаточно широкую вовлеченность заинтересованных сторон, действенные меры по внедрению цифровых технологий не были осуществлены, причиной чему, по заключению представителей французского бизнеса, является отсутствие у правительства Франции плана действий ${ }^{28}$.

По нашему мнению, перед французской экономикой стоит задача акцентировать больше внимания на производственном секторе и рыночном продвижении его продукции. В частности, этому должна способствовать инициатива «Сделано во Франции» (French Fab), нацеленная не столько на рост внутреннего потребления, сколько на продвижение французского производственного сектора на глобальных рынках.

\footnotetext{
${ }^{27}$ The Future of Manufacturing - France (2018). [Эл. pecypc]. URL: https:/gmisummit.com/ wp-content/uploads/2018/06/20180627_GMIS-France_vF.pdf (дата обращения: 06.10.2018).

${ }^{28}$ Industrie du futur: l'Etat donne un coup de pouce aux PME. [Эл. pecypc]. URL:

https://www.challenges.fr/entreprise/industrie-du-futur-1-etat-donne-un-coup-de-pouceaux-pme_614190 (дата обращения: 16.05.2019).
} 


\section{Программа "Сделать в Индии"}

Главное содержание анонсированной в 2014 г. программы Make in India состоит в проведении активной политики технологической модернизации и диверсификации структуры экономики путем ускоренного развития высокотехнологичных отраслей промышленности. Программа предусматривает увеличение доли добавленной стоимости обрабатывающей промышленности с $15 \%$ до $25 \%$ к 2022 г. и создание почти 100 млн новых рабочих мест.

Для стимулирования иностранных и национальных инвестиций в конкурентоспособные производства на территории страны в рамках программы была предусмотрена серьезная реформа законодательства, намечена отмена разрешительных процедур и ограничений на иностранное участие в ряде секторов (включая стратегические), упрощение и ускорение процедур, связанных с ведением бизнеса, модернизация инфраструктуры (строительство масштабных «индустриальных коридоров»грузовых магистралей: Дели - Мумбаи, Ченнаи - Бангалор, Амритсар - Калькутта) ${ }^{29}$, а также строительство «умных городов», оснащенных цифровыми технологиями в области безопасности, энергетики, водоснабжения, транспорта, управления отходами, здравоохранения, для повышения качества и комфортности для проживания.

Несмотря на провозглашенные принципы избирательности и приоритетности экономической политики, 25 направлений, включенных в перечень ключевых, покрывают большую часть экономики страны. Это авиа- и автомобильная промышленность, производство автокомпонентов, биотехнологии, химическая промышленность, строительство, оборонно-промышленный комплекс, электротехническое машиностроение, электронные системы, производство продовольственных товаров, информационные технологии, кожевенная промышленность, средства массовых коммуникаций, горнодобывающая, нефтяная и газовая промышленность, фармация, порты и судоходство.

\footnotetext{
${ }^{29}$ Make in India (2015). New Initiatives. [Эл. pecypc]. URL: https://www.ibef.org/economy/ make-in-india (дата обращения: 03.09.2018).
} 
В то же время в части критериев, на основании которых должны приниматься решения в экономической политике, приоритеты прослеживаются более четко, это:

- новые инициативы;

- прямые иностранные инвестиции;

- защита интеллектуальной собственности;

- развитие национальной перерабатывающей промышленности.

Хотя за прошедшие годы с начала реформ состояние экономики Индии значительно улучшилось: по динамике ВВП страна является одним из мировых лидеров, доля импорта в ВВП сократилась с $30 \%$ в 2005 г. до $22 \%$ в 2017 г., значительно улучшены позиции Индии в рейтинге Doing Bussiness (142-е место из 190 стран в 2013 г. и 77-е в 2019 г. в двух городах - Дели и Мумбаи) ${ }^{30}$, говорить об ощутимом влиянии программы Make in India на производственный сектор пока рано.

Изначально программа Make in India была ориентирована преимущественно на оборонный сектор. Согласно данным, опубликованным Стокгольмским международным институтом исследований проблем мира (SIPRI), Индия является крупнейшим в мире импортером основных видов вооружений, на ее долю приходится 13\% мирового объема импорта в период с 2012 по 2016 гг., в основном из России, США и Израиля.

По данным Всемирного банка, доля добавленной стоимости обрабатывающей промышленности Индии с 2015 г. по 2017 г. в текущих ценах выросла с $14 \%$ до 20\%, но в постоянных ценах 2010 г., в 2017 г. в сравнении с 2015 г. произошло ее сокращение на $0,17 \%{ }^{31}$. На отсутствие прогресса в достижении заявленных целей указывают и другие данные. С конца 2016 г. по конец 2017 г. валовое накопление основного капитала в процентах от ВВП упало с $30,8 \%$ до $28,5 \%$, притом что несколько лет назад этот показатель достигал 34-35\% ${ }^{32}$.

\footnotetext{
${ }^{30}$ Doing Business 2019 Indicators. [Эл. peсурc]. URL: http://russian.doingbusiness.org/ content/dam/doingBusiness/country/i/india/IND.pdf (дата обращения: 13.05.2019).

${ }^{31}$ The World Bank (2019). Data. [Эл. pecypc]. URL: https://data.worldbank.org/indicator/ NV.IND.MANF.KD?locations=IN (дата обращения: 13.05.2019).

${ }^{32}$ Chidambaram P. (2017). Why Modi's Make in India is a flop [Эл. pecypc]. URL: https://www.financialexpress.com/economy/the-make-in-india-flop-show/711912/ (дата обращения: 14.05.2019).
} 
Не было достигнуто заметного прогресса в улучшении транспортной инфраструктуры, снизились темпы прироста новых рабочих мест. Так, в 2015-2016 гг. было создано только 641 тыс. рабочих мест, что критично мало для такой страны, как Индия ${ }^{33}$.

Хотя Департамент промышленной политики и развития сообщил, что валовые ПИИ в Индию подскочили до 55,5 млрд долл. в 2015-2016 гг., что на 23,1\% больше, чем в 2014-2015 гг., данные Резервного банка Индии показывают, что прямые иностранные инвестиции в обрабатывающую промышленность упали до 8,4 млрд долл. (в 2015-2016 гг. было 9,6 млрд). Кроме того, доля ПИИ в производственный сектор, которая в течение последних четырех лет находилась в диапазоне 35-40\%, в 2015-16 гг. снизилась до $23 \%$. А согласно отчету Института исследований промышленного развития (ISID), ПИИ сократились почти на $30 \%$ в период с апреля 2016 г. по август 2017 г. ${ }^{34}$

Сокращение потребительских расходов - основного драйвера экономического роста, незначительный рост прямых инвестиций, а также снижение объемов экспорта замедлили прирост ВВП в 2018-2019 гг., что, по мнению члена Экономического консультативного совета премьер-министра Индии Нарендры Моди, Ратина Роя, является сигналом грядущего структурного кризиса ${ }^{35}$. Кроме того, обнаруженные ранее министерством статистики и выполнения программ Индии (NSSO) ложные данные и нестыковки в официальной макроэкономической статистике ставят под сомнение достигнутые результаты индийской экономики. Так, исследование, проведенное министерством торговли Индии, показывает, что некоторые из историй успеха Make in India могут быть скорее преувеличением, чем конкретными достижениями. Например, рост количества заводов по производству мобильных телефонов и сокращение их импорта из Китая с 6,3 млрд долл. до 3,3 млрд долл. в период с 2014 г.

${ }^{33}$ Dutt D'Cunha S. (2017). PM Modi Calls the World To 'Make in India,' But the Initiative Fails to Take Off. (2017). [Эл. pecypc]. URL: https://www.forbes.com/sites/ suparnadutt/2017/07/24/missing-the-mark-pm-modi-courts-the-world-to-make-in-indiabut-the-initiative-fails-to-take-off/ (дата обращения: 15.09.2018).

${ }^{34}$ Dutt D'Cunha S. (2017). PM Modi Calls the World To 'Make in India,' But the Initiative Fails to Take Off. (2017). [Эл. pecypc]. URL: https://www.forbes.com/sites/ suparnadutt/2017/07/24/missing-the-mark-pm-modi-courts-the-world-to-make-in-indiabut-the-initiative-fails-to-take-off/ (дата обращения: 15.09.2018).

35 Эксперт: экономика Индии перед лицом структурного кризиса. [Эл. pecypc]. URL: https://regnum.ru/news/2626328.html (дата обращения: 15.09.2018). 
по 2017 г. произошли при более значительном росте импорта телекоммуникационных частей из Китая за этот же период с 1,3 до 9,4 млрд долл. ${ }^{36}$

\section{Программа Made in China 2025}

В марте 2015 г. в Китае была анонсирована 10-летняя программа Made in China 2025, призванная стимулировать развитие умного производства (smart manufacturing), способного составить конкуренцию промышленности таких развитых стран, как Германия и США - от производства чипов до выпуска беспилотных автомобилей.

Программа предусматривает государственную поддержку 10 высокотехнологичных секторов: информационные технологии следующего поколения, высокопроизводительные машины и роботы с числовым программным управлением, аэрокосмическое и авиационное оборудование, морское инженерное оборудование и морское судопроизводство, современное железнодорожное оборудование, энергосберегающие и новые энергетические транспортные средства, электрооборудование, сельскохозяйственное машиностроение, новые материалы и биофармацевтические препараты и высокоэффективные медицинские устройства ${ }^{37}$. Планируется, что в программу будет инвестировано 300 млрд долл. бюджетных средств ${ }^{38}$, что составляет 2,45\% от ВВП 2017 г. $^{39}$ Фактически ставится задача стать глобальным технологическим лидером в этих секторах.

Другой важнейшей задачей программы Made in China 2025 является модернизация традиционных отраслей промышленности и их интеграция с новыми секторами.

К настоящему времени Китай уже занимает высокие позиции в ряде высокотехнологичных секторов экономики. Так, в 2017 г. на него приходилась почти треть всех устанавливаемых роботов

\footnotetext{
${ }^{36}$ India needs an industrial policy (2018). [Эл. pecypc]. URL: https://www.hindustantimes. com/editorials/india-needs-an-industrial-policy/story-KyXLQ3jIuUNOSLz2vmIveI.html (дата обращения: 15.09.2018).

${ }^{37}$ Made in China 2025 [Эл. pecypc]. URL: http://isdp.eu/content/uploads/2018/06/Madein-China-Backgrounder.pdf (дата обращения: 15.09.2018).

${ }^{38}$ Bradsher K., Mozur P. (2017). China's Plan to Build Its Own High-Tech Industries Worries Western Businesses [Эл. pecypc]. URL: https://www.nytimes.com/2017/03/07/business/ china-trade-manufacturing-europe.html?module=inline (дата обращения: 15.09.2018).

${ }^{39}$ World Bank. GDP (current US\$). [Эл. ресурс]. URL: https://data.worldbank.org/indicator/ NY.GDP.MKTP.CD?locations=CN (дата обращения: 29.03.2019).
} 
в мире. В 2020 г. число промышленных роботов в стране достигнет 950,3 тыс. единиц, что в 1,5 раза выше, чем прогнозируется для ЕС $(611,7 \text { тыс. единиц })^{40}$. Он также является мировым лидером в производстве литиевых батарей. К 2020 г. доля Китая в этой нише должна составить $62 \%$ от общего объема, за ним следуют США (22\%) и Южная Корея $(13 \%)^{41}$.

Китайская программа предусматривает таккже уровень самообеспеченности в 70\% для основных компонентов и материалов в таких отраслях, как аэрокосмическое и телекоммуникационное оборудование ${ }^{42}$. За счет внутреннего производства к 2025 г. должно быть покрыто до 60\% потребностей в оборудовании для ИКТ, $40 \%$ - чипов, используемых в смартфонах.

Большая часть продукции ключевых отраслей должна потребляться внутренним рынком. Если в авиации к 2025 г. китайские производители должны закрыть до 10\% внутренних потребностей в гражданских самолетах, то в космической промышленности, возобновляемой энергетики и энергосбережения - уже $80 \%$. В автомобилестроении - 80\% (по электрическим и гибридным автомобилям). В области сельскохозяйственного машиностроения доля внутреннего производства должна составить от 65 до 90\%, на рынке строительных материалов и материалов для текстильной промышленности - до 90\%, по важнейшим стратегическим материалам, включая редкоземельные и специальные сплавы до $85 \%$. По медицинскому оборудованию и приборам, где имеется существенная зависимость от импорта, перед китайскими производителями ставится задача обеспечить удовлетворение внутреннего спроса на 70\%.

Впрочем, экспортная экспансия китайских компаний тоже стоит в повестке дня. В частности, на мировом рынке морских судов последнего поколения Китай намеревается занять 80\% к 2025 г. Китайские компании, занимающиеся производством

${ }^{40}$ IFR (2018) Forecast: 1.7 million new robots to transform the world's factories by 2020. [Эл. ресурс]. URL: http;//ifr.org/ifr-press-releases/news/ifr-forecast-1.7 million-new-robotsto-transform-the-world's-factories-by-2020).

${ }^{41}$ Chinanew (2017). Made in China 2025. [Эл. pecypc]. URL: http://chinanew.tech/ made_in_china_2025_news) (дата обращения: 15.09.2018).

${ }^{42}$ Segal A. (2018). Why Does Everyone Hate Made in China 2025? March. 2018. [Эл. pecypc]. URL: https://www.cfr.org/blog/why-does-everyone-hate-made-china-2025 (дата обращения: 15.09.2018). 
современных железнодорожных поездов, к 2025 г. собираются направлять на экспорт до 40\% своей продукции ${ }^{43}$.

Не случайно ход реализации программы Made in China 2025 вызывает тревогу у традиционных торговых партнеров Китая, опасающихся потерять свои позиции как на китайском рынке, так и на мировом - за счет усиления конкуренции со стороны Китая. В развернувшейся в 2018-2019 гг. торговой войне США и Китая особые препоны были поставлены перед отраслями, которые вносят вклад в эту программу: администрация США ввела таможенные пошлины на солнечные батареи и импорт стали и алюминия. В июле и августе 2018 г. Соединенные Штаты применили 25-процентные пошлины на китайские товары на 50 млрд долл., а в сентябре 2018 г. - еще на 200 млрд долл. (правда, в этот раз пошлина была 10\%). В мае 2019 г., после провала очередных торговых переговоров с КНР, Вашингтон и эти пошлины увеличил до 25\%. Президент Д. Трамп заявил, что такие же тарифы могут быть установлены на весь объем импорта китайских товаров ${ }^{44}$.

Программа Made in China 2025 является первым этапом более масштабного трехфазного проекта, рассчитанного до 2050 г. и направленного на развитие внутренних технологических инноваций, создание и продвижение на мировые рынки китайских брендов. Стратегическая задача - превратить Китай в ведущую инновационную державу мира, 70\% продукции национальной промышленности должны работать в суперинновационных областях ${ }^{45}$.

В рамках этой программы правительство призывает крупнейшие компании существенно повысить расходы на НИОКР. Предусматривается разнообразная институциональная и финансовая государственная поддержка в реализации программы. В частности, к 2025 г. в стране будут созданы около 40 производственных инновационных центров.

\footnotetext{
${ }^{43}$ Reuters (2018). Factbox: Made in China 2025: Beijing's big ambitions from robots to chips. [Эл. pecypc]. URL: https://www.reuters.com/article/us-usa-trade-china-policyfactbox/factbox-made-in-china-2025-beijings-big-ambitions-from-robots-to-chips-id (дата обращения: 15.09.2018).

${ }^{44}$ James McBride J., Chatzky A. (2019). Is 'Made in China 2025' a Threat to Global Trade? [Эл. ресурс]. URL: https://www.cfr.org/backgrounder/made-china-2025-threat-global-trade (дата обращения: 15.05.2019).

${ }^{45}$ Михеев B. Осторожный, но настойчивый дракон. [Эл. pecypc]. URL: https://stimul online/articles/interview/ostorozhnyy-no-nastoychivyy-drakon/?sphrase_id=1951 (дата обращения: 15.09.2018).
} 
В качестве механизма достижения поставленных задач в КНР используется установление государственных целей и полуофициальная координация, побуждающая частные и государственные фирмы формировать свои решения в соответствии с плановыми приоритетами. Правительство осуществляет прямую поддержку промышленности за счет государственного финансирования, кредитов под низкие проценты, налоговых льгот и других субсидий на сотни миллиардов долларов. Китайские компании как государственные, на которые приходится около трети ВВП и $2 / 3$ исходящих инвестиций, так и частные (такие как Huawei и ZTE), поощряются к инвестированию в иностранные фирмы (в частности, в полупроводниковой отрасли), чтобы получить доступ к передовым технологиям. По некоторым оценкам, стоимость китайских приобретений в США в 2016 г. превысила 45 млрд долл. ${ }^{46}$

Ключевым шагом в достижении поставленной цели является создание «фонда талантов»-ученых, инженеров, предпринимателей. КНР вкладывает огромные финансовые ресурсы в образование и науку: на его долю приходится свыше 1/5 всех степеней бакалавра в области науки и техники, полученных во всем мире, что более чем вдвое превышает долю США. Число студентов, получающих высшее образование в области науки и техники в Китае, с 2002 по 2014 гг. увеличилось в четыре раза. Страна занимает второе место в мире после США по общему числу докторских диссертаций и первое - по количеству докторских степеней в области физики, математики и информатики. Кроме того, в период с 2000 по 2016 гг. Китай удвоил инвестиции в НИОКР, которые превысили 2\% ВВП, опередив ЕС.

И, хотя, как заявляют китайские политики, на разработку китайской инициативы «Китай 2025» их вдохновила германская «Индустрия 4.0», между этими двумя программами имеется ряд отличий:

- государственные субсидии Германии намного меньше, и они почти полностью направлены на фундаментальные исследования;

\footnotetext{
${ }^{46}$ James McBride J., Chatzky A. (2019). Is 'Made in China 2025' a Threat to Global Trade? [Эл. ресурс]. URL: https://www.cfr.org/backgrounder/made-china-2025-threat-global-trade (дата обращения: 15.05.2019).
} 
- в Германии отсутствуют целевые показатели для замены импорта или квоты на местное производство;

- экономика Германии в целом более открыта для иностранных инвестиций и конкуренции.

\section{А не пора ли «Сделать в России»}

Опыт почти двух десятков государств мира, различных по своему политическому и социально-экономическому устройству и уровню экономического развития, показывает, что они стремятся обеспечить свою структурно-технологическую модернизацию с помощью специальных программ умной реиндустриализации. Этот опыт не однозначен: где-то он более успешен, где-то реальные результаты могут проявиться в среднесрочной перспективе. Но показателен тот факт, что ни одна из стран не отказалась от принятых программ и продолжает их совершенствование с целью более адекватной реакции на технологический прогресс, связанный с четвертой промышленной революцией.

В России в настоящее время вопросы структурно-технологической модернизации также фигурируют на переднем плане экономической политики. Президент РФ В.В. Путин в своих выступлениях неоднократно подчеркивал жизненную необходимость технологического прорыва, «изменения структуры экономики для обеспечения развития на перспективу» ${ }^{47}$.

Решение этих задач с мая 2018 г. возлагается на 13 национальных проектов, реализация которых потребует более 25 трлн руб. В то же время есть опасения, что выполнение этих проектов не приведет к остро необходимым структурным сдвигам в экономике и экспорте. Такие преобразования невозможно осуществить без эффективного стратегического планирования, закон о котором был принят еще в 2014 г. В этом смысле нацпроекты не являются инструментами целенаправленного преобразования структуры российской экономики и экспорта. Прописанные в них «меры» представляют собой скорее общие пожелания, не имеющие конкретных сроков реализации с четко обозначенными задачами.

\footnotetext{
${ }^{47}$ Дружинин А. (2019) Путин: Сверхзадачей для РФ должно быть изменение структуры экономики. URL: https://1prime.ru/state_regulation/20190424/829925842.html).
} 
Как сообщает пресс-служба Счетной палаты РФ, существует риск ненадлежащей реализации нацпроектов и недостижения национальных целей из-за проблем с освоением предусмотренных для этого бюджетных средств субъектами РФ. По состоянию на 1 марта 2019 г. (т.е. спустя 9 месяцев после появления соответствующего указа президента) по всем национальным проектам исполнение составило лишь $5,8 \%$ от запланированных показателей ${ }^{48}$.

Существенной недоработкой нацпроектов является отсутствие системы мониторинга и контроля за выполнением поставленных целей, чрезмерно растянутые сроки на «раскачку». Так, Национальный проект «Цифровая экономика» во многом сохраняет риторический характер предшествующей ему программы с одноименным названием. Его разработка ведется в отсутствие проработанной долгосрочной стратегии социально-экономического развития, в результате чего не решается вопрос увязки с другими нацпроектами и программами государства, реальными запросами и потребностями бизнеса.

Нет проработанных планов и других ключевых областей, без развития которых невозможно представить наше будущее (биотехнологии, искусственный интеллект, фотоника и электроника, дроны и роботы, квантовые компьютеры, прогрессивные материалы и т.п.).

На наш взгляд, эти проблемы можно было бы решить с помощью разработки десятилетней программы «Сделать в России 2030». В отличие от нацпроектов, такая программа должна содержать конкретные показатели, включая промежуточные цели (на 2025 г.), что позволит ей стать реальным документом стратегического планирования. При этом должен быть обеспечен четкий контроль за ходом ее выполнения - во избежание превращения ее в очередной «воздушный замок», которых немало было в нашей экономической истории. Реальное же содержание и особенности механизма реализации программы «Сделать в России 2025» заслуживают отдельного исследования, в котором, безусловно должен быть учтен положительный зарубежный опыт.

${ }^{48}$ Счетная палата (2019). URL: https://tass.ru/nacionalnye-proekty/6271344). 


\section{Литература}

Белов В.Б. Новая парадигма промышленного развития Германии - стратегия «индустрия 4.0» // Современная Европа. 2016. № 5. С. 11-22.

Ленчук Е.Б. Формирование инновационной модели развития России: работа над ошибками // Вестник Института экономики РАН. 2018. № 1. С. 36.

Хейфеи Б. А. Новые экономические мегапартнерства и Россия. СПб.: Алетейя, 2019. 288 с.

Шваб К. Четвертая промышленная революция. М.: Эксмо, 2016. 139 с.

Kheyfets B.A., Chernova V.Y. (2018). Tools for estimating the effectiveness of import-substituting modernization: case in the agriculture of Russia // European Research Studies Journal. 2018. № 3 (21). Pp. 179-191.

Kheyfets B.A., Chernova V.Y., Degtereva E.A. Prospects and threats of implementing the export-oriented import substitution policy in the EEU territory // WSEAS Transactions on Business and Economics. 2018. T. 15. Pp. 404-412.

Статья поступила 08.05.2019.

Для цитирования: Хейфец Б.А., Чернова В. Ю. Зарубежные программы умной реиндустриализации: варианты для России// ЭКО. 2019. № 8. С. 118-140. DOI: 10.30680/ECO0131-7652-2019-8-118-140.

\section{Summary}

Kheyfets, B.A., Doct. Sci. (Econ.), Institute of Economics, RAS, Financial University under the Government of the Russian Federation

Chernova, V. Yu., Cand. Sci. (Econ.), RUDN University, Moscow

Experience of Foreign Countries in Reindustrialization: Lessons for Russia

Abstract. The article discusses the experience of France and Germany, China, India in the implementation of structural and technological modernization of the economy with the help of new strategic management tools. The main features of the programs are: innovative nature, focus on the implementation of structural changes in the economy, selectivity, focus on achieving specific results, import-substituting character in countries with transition economies. Although these programs affect the entire economy, they have their own priorities. These priorities are different for individual countries, but for all of them, the priorities of the accelerated introduction of technologies of the fourth industrial revolution come out on top. These programs are aimed at implementing fundamental structural changes, focusing on achieving concrete results in the medium term for 10-15 years. Foreign programs of structural and technological modernization also involve the introduction of new technologies in traditional sectors of the economy, that is, they have a synergistic effect on economic development. It is shown that despite the ambiguity of the results achieved, none of the countries refused to accept the adopted programs and continue their improvement in order to more adequately respond to the technological progress associated with the fourth industrial revolution. The tasks set in foreign programs of smart reindustrialization are extremely relevant for the Russian economy and deserve careful study and adaptation to our realities. It was noted that the essential shortcomings of the national projects are the lack of a monitoring and control system for the implementation of the goals set and excessively prolonged periods of "buildup"; 
lack of a well-developed long-term strategy for socio-economic development; the lack of well-developed plans in a number of key areas that determine the country's digital future. The conclusion is made about the need to introduce strategic planning tools into national projects for the purposeful transformation of the structure of the Russian economy and its exports.

Keywords: smart re-industrialization; re-industrialization strategies; industry 4.0; structural and technological modernization; structural policy; "Make Russia $2030 "$

\section{References}

Belov, V.B. (2016). Novaya paradigma promyshlennogo razvitiya Germanii strategiya «industriya 4.0». Sovremennaya Evropa. No. 5. Pp.11-22. (In Russ.).

Kheyfets, B.A. (2019). New economic megapartnerships and Russia St. Petersburg. Aletheia Publ. 288 p. (In Russ.).

Kheyfets, B.A., Chernova, V.Y., Degtereva, E.A. (2018). Prospects and threats of implementing the export-oriented import substitution policy in the EEU territory. WSEAS Transactions on Business and Economics. No. 15. Pp. 404-412.

Kheyfets, B.A., Chernova, V.Y. (2018). Tools for estimating the effectiveness of import-substituting modernization: case in the agriculture of Russia. European Research Studies Journal. No. 3 (21). Pp. 179-191.

Lenchuk, E.B. (2018). Formirovanie innovacionnoj modeli razvitiya Rossii: rabota nad oshibkami. Vestnik Instituta ehkonomiki RAN. No. 1. P. 36. (In Russ.).

Shvab K. (2016). The fourth industrial revolution. Moscow, Eksmo Publ. 139 p. (In Russ.).

For citation: Kheyfets, B.A., Chernova, V. Yu. (2019). Experience of Foreign Countries in Reindustrialization: Lessons for Russia. ECO. No. 8. Pp. 118-140. (In Russ.). DOI: 10.30680/ECO0131-7652-2019-8-118-140. 